\title{
Implementasi Policy Base Routing dan Failover Menggunakan Router Mikrotik untuk Membagi Jalur Akses Internet di FMIPA Unnes
}

\author{
Ryo Pambudi *), Much Aziz Muslim \\ Program Studi Teknik Informatika, Fakultas MIPA, Universitas Negeri Semarang \\ Jl. Taman Siswa, Kampus Unnes Sekaran, Semarang, Indonesia 502295
}

\begin{abstract}
Increasing requirement for information in every year become an important requirement for every society, organizations, and others institution. Semarang State University (Unnes) had using online information systems in every aspect. It needs high speed and reliable internet connection, so the using of two Internet Service Provider (ISP) or public pathways are highly commended. Internet access point density due to the number of users such as students, faculty, and employees to be one of the factors that can interfere with such information systems. Routing settings on Mikrotik router become one of the solutions to reduce density access of internet. The useful of policy-base routing is to separate the path which will be passed when the accessing the Internet and the useful of failover technique is to move path automatically if one access point (ISP) impaired / down. Comparison before and after applying these two techniques while accessing the Unnes information systems results increasing access speed with $4 \mathrm{~ms}$ response time faster than before used policy base routing.
\end{abstract}

Keywords - internet; information system; router; base policy routing; failover

Abstrak - Pertumbuhan dan kebutuhan akan informasi semakin tahun menjadi sebuah kebutuhan vital bagi setiap masyarakat pada umumnya dan bagi organisasi maupun lembaga pendidikan pada khususnya. Universitas Negeri Semarang (Unnes) yang telah lama menggunakan sistem informasi secara online dalam setiap aspek, membutuhkan internet yang cepat dan handal sehingga penggunaan dua Internet Service Provider (ISP) atau jalur publik sangat dianjurkan. Kepadatan jalur akses internet akibat banyaknya pengguna yaitu mahasiswa, dosen, dan karyawan menjadi salah satu faktor yang dapat mengganggu sistem-sistem informasi tersebut. Pengaturan routing pada router Mikrotik menjadi salah satu solusi untuk mengurangi kepadatan jalur akses internet. Policy base routing dapat berguna untuk memisahkan jalur mana yang akan dilewati pengguna saat mengakses internet dan teknik failover berguna untuk memindahkan jalur otomatis jika salah satu jalur akses (ISP) mengalami gangguan/down. Perbandingan sebelum dan setelah menerapkan kedua teknik tersebut saat mengakses sistem-sistem informasi milik Unnes menunjukkan tingkat hasil kecepatan akses yang berbeda, yang

*) Penulis Korespondensi (Ryo Pambudi)

Email: ryopambudi@gmail.com menghasilkan waktu response lebih cepat 4 ms dibandingkan sebelum penggunaan policy base routing.

Kata Kunci - internet; sistem informasi; router; policy base routing; failover

\section{Pendahuluan}

Perkembangan teknologi informasi dan internet di Indonesia setiap tahun menunjukkan kemajuan yang sangat pesat dari segi infrastruktur, pengguna, perangkat keras (hardware), perangkat lunak (software) dan sistem informasi yang handal. Penggunaan teknologi komputer dan internet menjadi acuan yang dapat memaksimalkan hasil dan kualitas dari sebuah sistem [1]. Infrastruktur teknologi informasi khususnya internet yang semakin baik juga membutuhkan manajemen yang baik untuk menjaga kelancaran akses dari para pengguna [2].

Fakultas Matematika dan Ilmu Pengetahuan Alam (FMIPA) adalah salah satu fakultas di Unnes yang memiliki jumlah mahasiswa dan dosen terbanyak, sehingga penggunaan akan kebutuhan internet di fakultas ini sangat tinggi. Sistem informasi yang telah tersedia di Unnes untuk proses penyelenggaraan akademik dan administrasi harus dapat diakses secara cepat dan mudah karena sangat berpengaruh terhadap proses berjalannya perkuliahan [3],[4]. Manajemen terhadap infrastruktur internet berguna untuk mengoordinasi setiap jalur akses intenet agar pengguna dapat mengakses sistem informasi secara cepat.

Manajemen terhadap infrastruktur internet dilakukan dengan pengaturan routing yang tepat pada router yang ada di FMIPA dan penggunaan dua jalur publik/internet sehingga tidak terjadi kepadatan pada jalur akses. Router berfungsi untuk membentuk dan menghubungkan sebuah jaringan baru yang selaras dengan jaringan dari ISP sehingga setiap pengguna dalam jaringan tersebut dapat saling berkomunikasi [5]. Router Mikrotik dapat dijadikan sebagai gateway yang mendistribusikan akses data dari satu komputer ke komputer lainnya sehingga mempengaruhi cepat lambatya proses pengiriman data yang ada dalam sebuah jaringan [6]. Konfigurasi router Mikrotik dapat menggunakan aplikasi WinBox yang dapat dijalankan di sistem operasi Windows untuk memudahkan konfigurasi [7].

Sering terjadinya kendala pada saat mengakses internet dan sistem informasi disebabkan oleh penuhnya trafik dikarenakan banyak pengguna yang mengakses kedua hal tersebut secara bersamaan dan gangguan dari ISP yang mengalami gangguan. Saat salah satu ISP 
mengalami gangguan, maka dibutuhkan ISP cadangan untuk memberikan dukungan sebagai jalur akses utama, dan diperlukan konfigurasi router yang dapat memindahkan jalur akses secara otomatis yaitu dengan teknik failover [8],[9].

Failover merupakan kemampuan sebuah sistem dalam hal ini router untuk dapat berpindah jalur akses secara otomatis jika salah satu sistem down sehingga menjadi backup untuk sistem yang mengalami down [10]. Penuhnya trafik dapat diatasi dengan pembagian jalur akses yang akan dilalui oleh pengguna, sehingga pengguna yang akan mengakses internet dan sistem informasi akan melalui jalur yang berbeda unruk mengurangi beban yang dihasilkan. Policy base routing merupakan metode penandaan routing yang ditetapkan oleh pengguna dan IP sebagai parameternya. Penggunaan policy base routing yang dapat mengatur dan membagi jalur akses para pengguna dan teknik failover yang dapat berpindah jalur secara otomatis saat salah satu jalur publik atau Internet Service Provider (ISP) mengalami down dapat menjadi solusi sebagai manajemen jaringan yang terbaik. Artikel ini membahas penerapan teknik policy based routing dan failover tehadap dua jalur publik pada router Mikrotik di jaringan FMIPA. Analisis dampak penggunaan kedua teknik tersebut meliputi pengujian waktu respon akses sebelum dan setelah teknik diterapkan serta fungsional failover.

\section{Metode DAN BAHAN}

Metode yang digunakan adalah metode pengembangan sistem, yang terdiri dari analisa kebutuhan, desain jaringan, tahap konfigurasi, pengujian dan penerapan. Tahap pertama adalah tahap analisa kebutuhan perangkat lunak dan perangkat keras. Perangkat lunak yang dibutuhkan yaitu sistem operasi Windows 10 Pro, Mikrotik Router OS v6.32.3, dan aplikasi Winbox untuk melakukan konfigurasi router mikrotik. Perangkat keras yang digunakan adalah laptop ASUS A43SD dengan prosesor Intel Core i3 dan $R A M$ sebesar 4GB serta Mikrotik Routerboard 951-2n yang memiliki prosesor AR9331-AL1A dan memori $32 \mathrm{MB}$.

Tahap kedua yaitu desain jaringan. Desain jaringan meliputi pembuatan topologi jaringan yang sesuai dengan kebutuhan, dan dapat menghasilkan kinerja yang baik. Tahapan ketiga adalah tahap konfigurasi. Konfigurasi router Mikrotik dengan menggunakan aplikasi winbox, terdapat beberapa konfigurasi yang akan dilakukan yaitu konfigurasi dasar, konfigurasi policy base routing dan konfigurasi failover.

Tahap keempat adalah pengujian. Pengujian dilakukan terhadap teknik policy base routing dan failover agar bekerja sebagaimana mestinya. Tahap kelima yaitu penerapan. Pada tahap ini, teknik policy base routing dan failover diterapkan dan dianalisa sehingga dapat diketahui apakah hasil yang ditunjukkan sesuai dengan rencana awal.

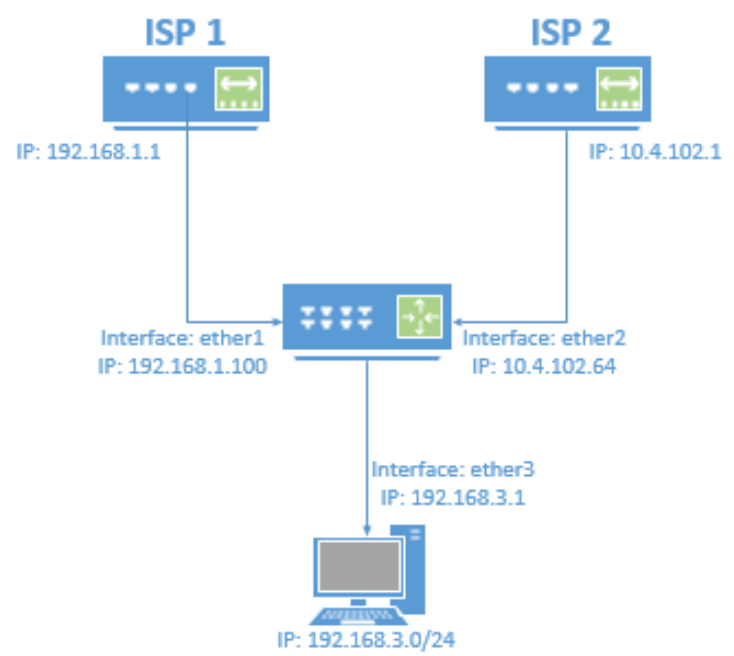

Gambar 1. Topologi Jaringan LAN dengan 2 jalur ISP dan 1 jalur lokal

\section{Hasil Dan Pembahasan}

Pada tahap ini akan dibahas tentang hasil penerapan teknik policy base routing dan failover, meliputi desain jaringan, konfigurasi, pengujian dan analisis. Desain jaringan digunakan untuk memilih dan merancang topologi jaringan yang sesuai. Untuk menerapkan policy base routing dan failover, dibutuhkan lebih dari satu IP publik. Dalam penelitian ini dibuat 3 buah jaringan yang terdiri dari dua jalur publik/internet dan satu jalur lokal sebagai akses pengguna dalam pengujian, seperti yang ditunjukkan pada Gambar 1 .

Konfigurasi dasar pada mikrotik dapat menggunakan software khusus yang digunakan yaitu Winbox. Konfigurasi dasar meliputi konfigurasi IP address, domain name system (DNS), dan NAT. Konfigurasi IP addres dapat menggunakan perintah sebagai berikut:

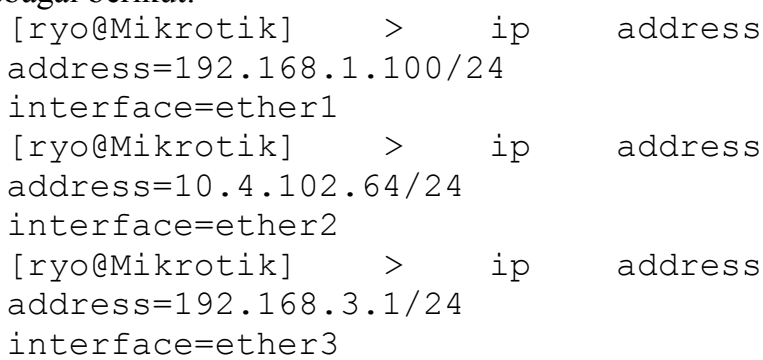

Konfigurasi DNS dapat menggunakan perintah sebagai berikut:

[ryo@Mikrotik] > ip dns set servers $=8.8 \cdot 8 \cdot 8,8.8 .4 .4$

Konfigurasi NAT dapat menggunakan perintah sebagai berikut:

[ryo@Mikrotik] > ip firewall nat add chain=srcnat action=masquerade outinterface=ether 1

[ryo@Mikrotik] > ip firewall nat add chain=srcnat action=masquerade outinterface=ether2 


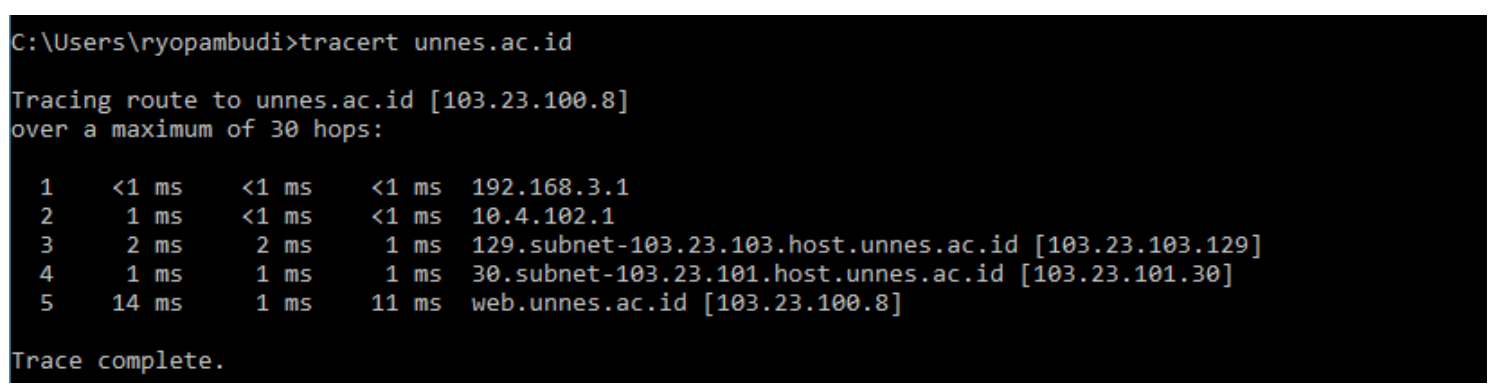

Gambar 2. Tracert http://unnes.ac.id

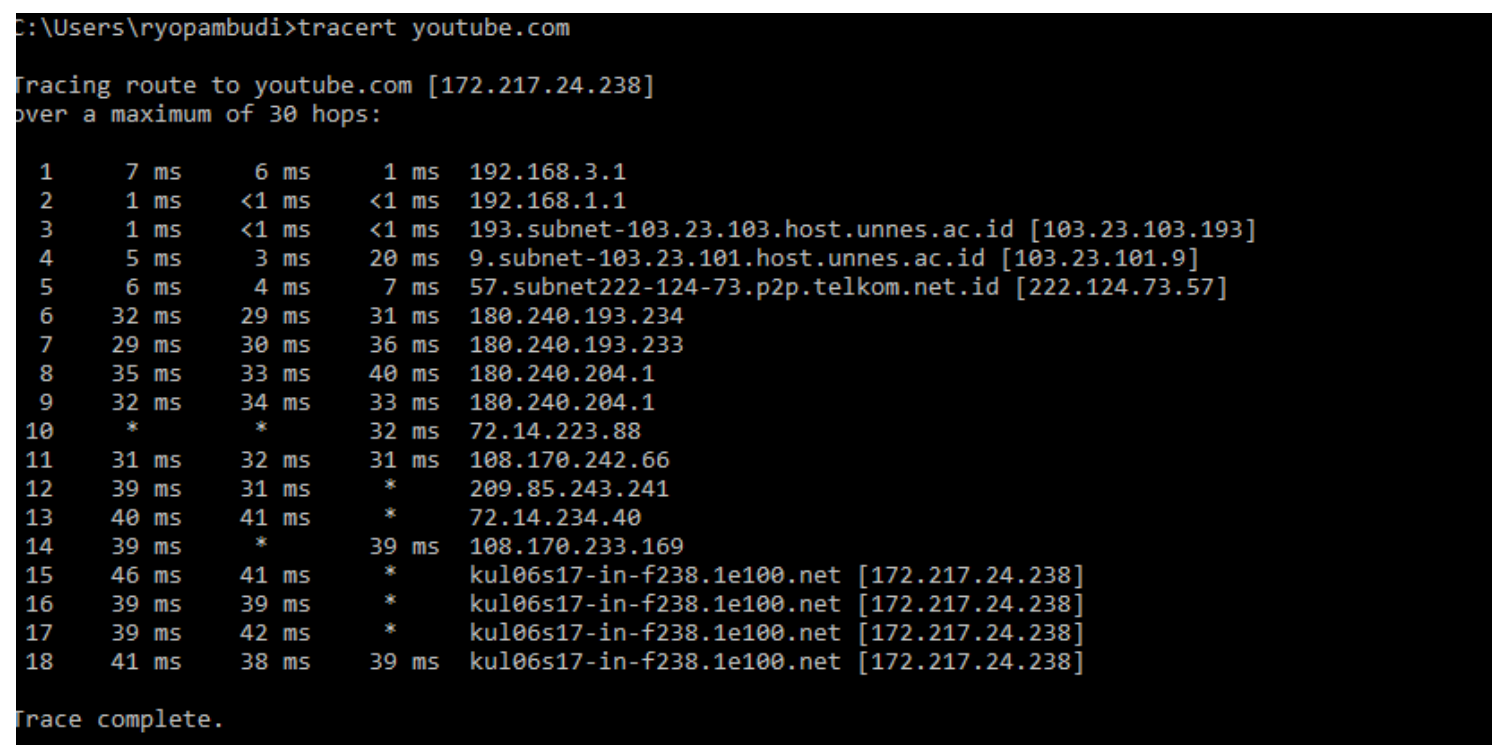

Gambar 3. Tracert http://youtube.com

Konfigurasi policy base routing meliputi konfigurasi mangle, ip address list, dan gateway. Konfigurasi Mangle dapat menggunakan perintah sebagai berikut:

[ryo@Mikrotik] > ip firewall mangle add chain=prerouting action=markrouting new-routing-mark=packetunnes passthrough=yes srcaddress $=192.168 .3 .0 / 24$ dst-addresslist $=$ unnes in-interface=ether 3

[ryo@Mikrotik] > ip firewall mangle add chain=prerouting action=markrouting new-routing-mark=packetinternational passthrough=yes srcaddress $=! 192.168 .3 .0 / 24$ dst-addresslist $=$ ! unnes in-interface=ether 3

Konfigurasi IP Address List dapat menggunakan perintah sebagai berikut:

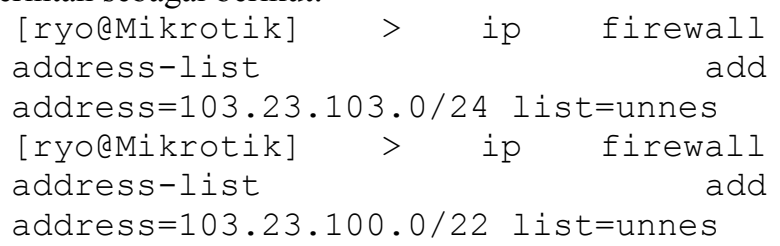

Konfigurasi Gateway dapat menggunakan perintah sebagai berikut:

[ryo@Mikrotik] > ip route add gateway=192.168.1.1 routingmark=packet-international distance $=1$

\begin{abstract}
[ryo@Mikrotik] > ip route add gateway=192.168.1.1 routingmark=packet-unnes distance $=1$
\end{abstract}

Konfigurasi Failover dapat menggunakan perintah sebagai berikut:

[ryo@Mikrotik] > ip route add gateway=192.168.1.1 distance=1

[ryo@Mikrotik] > ip route add gateway=10.4.102.1 distance=2

Pengujian terhadap IP policy base routing dapat menggunakan perintah Tracert yang ada di dalam command prompt (cmd) pada Windows. Tracert digunakan untuk menentukan rute yang dilewati paket Internet Control Message Protocol (ICMP) untuk mencapai tujuan. Dalam paket ini, tracert menggunakan nilai IP Time To Live (TTL) yang berbeda-beda. Karena setiap perute ke jalur yang diperlukan untuk menurunkan paket TTL oleh setidaknya 1 sebelum meneruskan paket. Saat TTL pada paket mencapai nol (0), router mengirim ICMP pesan "Request time out" kembali ke komputer sumber. Berikut Tracert yang dilakukan terhadap akses ke sistem informasi unnes pada link unnes.ac.id, seperti pada Gambar 2.

Pengujian kedua dilakukan terhadap akses internet international. Tracert yang dilakukan terhadap akses ke salah satu jaringan internet international yaitu link youtube.com ditunjukkan pada Gambar 3. 


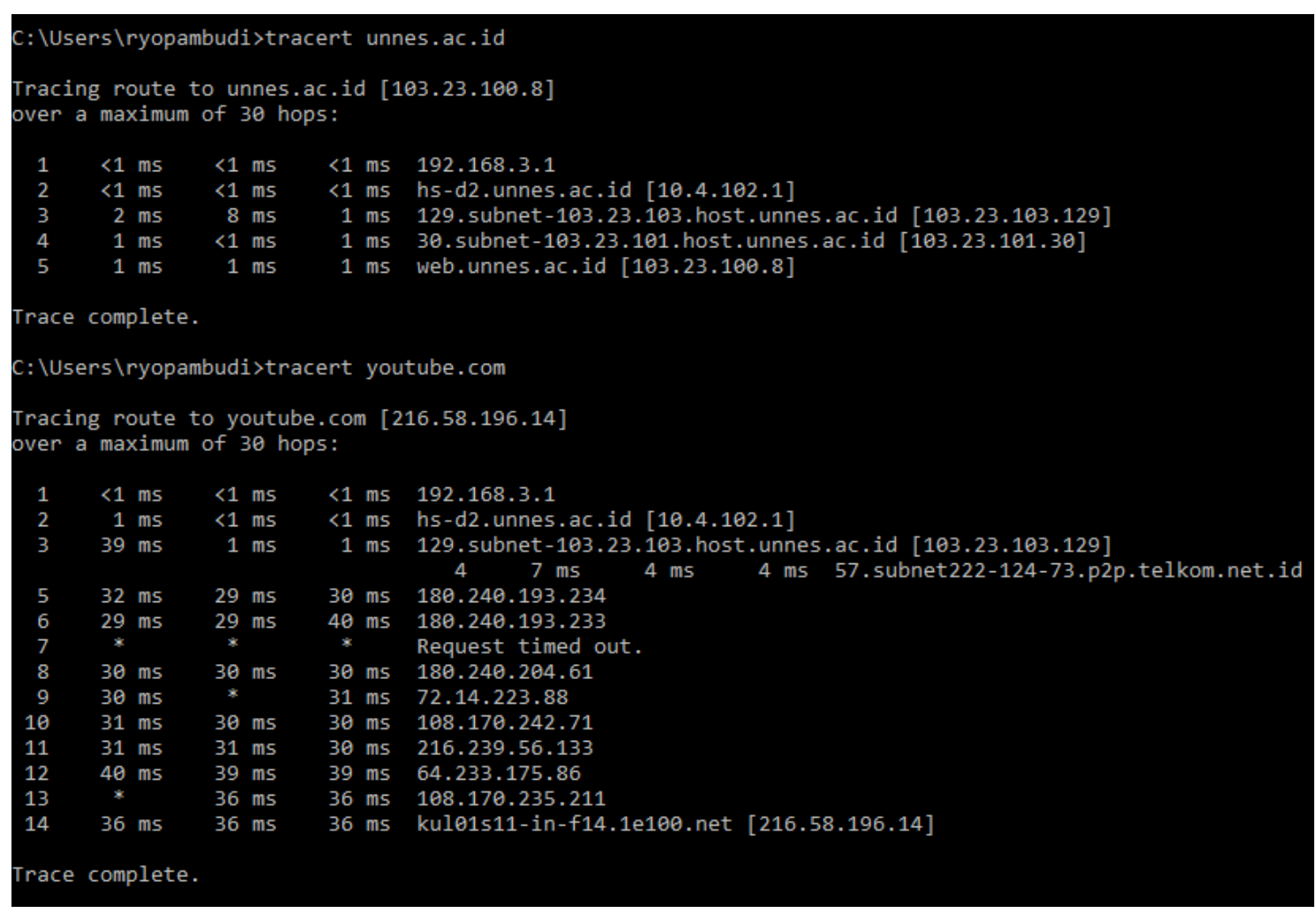

Gambar 4. Pengujian Failover

Tabel 1. Pengujian waktu respon

\begin{tabular}{ccc}
$\begin{array}{c}\text { Uji Coba } \\
\text { ping } \\
\text { unnes.ac.id } \\
\text { (ke- })\end{array}$ & $\begin{array}{c}\text { Response time } \\
\text { sebelum } \\
\text { penggunaan IP } \\
\text { Policy }(\mathbf{m s})\end{array}$ & $\begin{array}{c}\text { Response time } \\
\text { setelah } \\
\text { penggunaan IP } \\
\text { Policy }(\mathbf{m s})\end{array}$ \\
\hline 1 & 6 & 1 \\
2 & 2 & 1 \\
3 & 3 & 5 \\
4 & 4 & 1 \\
5 & 6 & 3 \\
6 & 4 & 1 \\
7 & 5 & 1 \\
8 & 5 & 1 \\
9 & 6 & 1 \\
10 & 5 & 1 \\
\hline Rata-rata & $\mathbf{4 , 6}$ & $\mathbf{1 , 6}$ \\
\hline
\end{tabular}

Simulasi dilakukan untuk melakukan pengujian terhadap failover. Pada Simulasi ini jalur internet pada ISP 1 dinonaktifkan sehingga mengalami down pada ISP 1. Maka secara otomatis ISP 2 yang digunakan sebagai jalur publik ke dua dan juga bertindak sebagai jalur khusus untuk sistem-sistem informasi pada unnesakan menjadi backup/cadangan. Jadi semua jalur akses ke internet akan dipindahakan ke jalur ISP 2, yang dapat dilihat pada Gambar 4.

Analisis perbandingan kecepatan uji akses ke link Unnes dilakukan dengan menggunakan ping dan sebagai acuan yaitu waktu respons yang dibutuhkan. Semakin kecil waktu respons yang dibutuhkan maka akses yang didapatkan untuk menuju ke server akan semakin cepat. Hasil pengujian perbandingan sebelum dan setelah penggunaan policy base routing terdapat pada Tabel 1.

Hasil pengujian pada Tabel 1 menunjukkan bahwa waktu respons yang dibutuhkan untuk mengakses sistem informasi Unnes sebelum menggunakan policy base routing yaitu 4,6 ms dan setelah menggunakan policy base routing menghasilkan peningkatan hanya membutuhkan waktu respons 1,6 ms. Dari hasil penelitian tersebut, dapat disimpulkan bahwa membagi jalur antara internet dan sistem informasi suatu instansi dapat dilakukan dan mengurangi beban pada kecepatan jalur akses, yang pada penelitianpenelitian sebelumnya hanya dilakukan untuk membagi beban penggunaan internet saja [1],[2],[5-10]. Failover juga dapat berjalan dengan baik. Failover ini dapat meminimalkan waktu yang dihasilkan saat terjadi gangguan pada jalur akses utama dibandingkan dengan seorang teknisi jaringan memindahkan dan mengkonfigurasi sistem pada router secara manual [6].

\section{KESIMPULAN}

Berdasarkan hasil penelitian yang didapat maka dapat disimpulkan bahwa penggunaan policy base routing dapat memisahkan jalur akses pengguna ke internet dan dapat mempercepat akses ke sistem informasi di Unnes yang dibuktikan dengan hasil pengujian ping yang membutuhkan sedikit waktu respon dari yang sebelumnya yaitu dari sebelumnya yang membutuhkan waktu 4,6 ms hanya membutuhkan $1,6 \mathrm{~ms}$ atau menghasilkan peningkatan waktu respons sebesar $4 \mathrm{~ms}$, serta failover dapat berfungsi sebagai 
backup sehingga tidak terjadi kegagalan akses internet saat ISP utama terjadi gangguan.

\section{Daftar Pustaka}

[1] F. J. Bhayangkara, and I. Riadi, "Implementasi Proxy Server dan Load Balancing Menggunakan Metode Per Connection Classifier (PCC) Berbasis Mikrotik (Studi kasus: Shmily.net)", Jurnal Sarjana Teknik Informatika, vol.2, no.2, 2014

[2] D. Sutadi, G. Bilardo, R. Bastian, and R., B. Mulianto, "Analisis dan Optimalisasi Jaringan Pada Pt Next Generation Wave", Jurnal Teknik Komputer, vol.20, no.01, 2012

[3] M. A. Muslim, "Pengembangan Sistem Informasi Jurusan Berbasis Web untuk Meningkatkan Pelayanan dan Akses Informasi”, Jurnal MIPA, vol.35, no.1, 2012

[4] T. Andrasto, "Pengembangan Sistem Database Hasil Penelitian dan Pengabdian Kepada Masyarakat Dosen Unnes", Jurnal Teknik Elektro, vol.5, no. 2,2015

[5] F. R. Doni, "Optimalisasi Jaringan Wireless Dengan Router Mikrotik Studi Kasus Kampus BSI Tangerang”, Evolusi, vol.2, no.1, 2015
[6] R. R. Shofiyan, "IP Policy Based Routing Simple Load Balancing Metode PCC Dengan Failover Queue Tree Model PCQ Di MikroTik Pada Badan Meteorologi Klimatologi Dan Geofisika (BMKG)", Skripsi, Universitas Dian Nuswantoro, 2014.

[7] I. E. Putra, "Perancangan Jaringan Hotspot Berbasis Mikrotik Router OS 3.3.0”, Jurnal TeknoIf, vol.1, no.1, 2013

[8] Y. Osadhani, I. Wijaya, and A. S. Pratama, "Analisis dan Implementasi Teknik Failover dan Filtering Content pada PT. Budiman Sejahtera Development", PhD. Thesis, BINUS, Indonesia, 2015.

[9] A. E. Maulana, B. Pawitra, E. Setiawan, and R. Shaleh, "Sistem Optimasi Pembebanan Jaringan dengan Koneksi Internet Ganda Menggunakan Mikrotik 2012", PhD. Thesis, BINUS, Indonesia, 2012.

[10] E. Arianto, M. Sholeh, and E. K. Nurnawati, "Implementasi Load Balancing Dua Line ISP Menggunakan Mikrotik RouterOS Studi Kasus Sistem Jaringan LAN di PT. Wahana Semesta Bangka (Babel Pos)", Jurnal Jarkom, vol.1, no.2, 2014 